\title{
Trace conditioning as an inhibitory procedure
}

\author{
RILEY E. HINSON AND SHEPARD SIEGEL \\ McMaster University, Hamilton, Ontario L8S 4K1, Canada
}

\begin{abstract}
Virtually no evidence of excitatory CR acquisition is observed in rabbit eyelid conditioning with a trace-conditioning procedure if the CS-UCS trace interval is greater than a few seconds. The lack of overt CRs following training with a trace-conditioning procedure has traditionally been interpreted as due to the passive decay of the CS stimulus trace over time. However, it is conceivable that a trace interval sufficiently long to preclude CR acquisition may be sufficiently long to teach the subject that the CS signals a UCS-free period, thereby producing an inhibitory CS. To test this proposal, eyelid conditioning in rabbits was conducted in two experiments with a 10-sec trace interval (there being no evidence of excitatory conditioning with this procedure). The trace-CS was then tested for evidence of inhibition with retardation-of-acquisition and summation tests. The trace-CS was shown to have conditional inhibitory properties. These results indicate that the interstimulus interval function in trace conditioning may be determined, in part, by inhibitory associations.
\end{abstract}

The classical trace conditioning paradigm is characterized by conditional stimulus (CS) offset before unconditional stimulus (UCS) onset. Following Pavlov (1927) and Hull (1943), it has generally been assumed that trace conditioning can be successful only if the perseverative central activity initiated by the terminated CS (i.e., the CS trace) is temporally contiguous with UCS onset. Consequently, when no excitatory conditioning is observed with a trace procedure, it is assumed that the trace interval is so long that the CS trace has completely decayed by the time of UCS presentation. The implication of this analysis is that nothing is learned about the CS-UCS relationship in a trace procedure when no overt conditional responses (CRs) occur.

However, failure to observe overt CRs following any particular arrangement of CS and UCS does not mean that the training procedure was associatively neutral (see Rescorla, 1969; Sears, Baker, \& Frey, 1979). For example, although extensive backwardpaired UCS-CS presentations do not elicit overt CRs, it its an effective inhibitory training procedure (Moscovitch \& LoLordo, 1968; Siegel \& Domjan, $1971,1974)$. Conditional inhibition in the backwardconditioning procedure presumably results from the pairing of the CS with a period free of the UCS, the intertrial interval (Moscovitch \& LoLordo, 1968). It is possible that nonexcitatory trace conditioning may

This research was supported by Research Grant APA-0298 from the National Research Council of Canada. Portions of this research were presented at the 38 th annual meeting of the Canadian Psychological Association, Vancouver, British Columbia, June 1977. We thank F. J. Barrera, M. Krank, and M. Feldman for their comments on earlier versions of the manuscript. Requests for reprints should be sent to Riley Hinson, who now is at the Addiction Research Foundation, 33 Russell Street, Toronto, Ontario M5S 2S1, Canada. involve a similar inhibitory learning process. That is, a trace interval sufficiently long to preclude $C R$ acquisition may be sufficiently long to teach the subject that the CS signals a UCS-free period-in this case, the CS-UCS trace interval.

If the trace CS that shows no evidence of excitatory properties is, in fact, inhibitory, it should be possible to detect this inhibition using the techniques summarized by Rescorla (1969): The inhibitory CS should be retarded in acquiring excitatory properties (retardation-of-acquisition test), and, when compounded with a known excitatory $C S$, it should reduce the magnitude of conditional responding (summation test). The present experiments applied these tests to a nonexcitatory trace $\mathrm{CS}$, using the rabbit eyelidconditioning preparation.

\section{EXPERIMENT 1}

The purpose of the first experiment was to determine if trace conditioning with a trace interval of too great a duration for overt excitatory CRs to occur causes the CS to subsequently be retarded in acquiring excitatory properties.

\footnotetext{
Method

Subjects and Apparatus. The subjects were 71 experimentally naive male New Zealand White rabbits, approximately 8-10 weeks old at the beginning of the experiment. All subjects were individually housed and allowed free access to food and water throughout the experiment.

Conditioning was carried out in six identical, sound-attenuated, ventilated chambers (Scientific Prototype Model SPO 300), with illumination provided by a $7.5-\mathrm{W}$ bulb located in the ceiling of each chamber. During each session, the rabbits were restrained in $18 \times 14 \times 41 \mathrm{~cm}$ Plexiglas boxes located within each chamber. The outer eyelid response was recorded with a modification of the technique described by Gormezano (1966). Briefly, movement of the rabbit's left outer eyelid was conducted, via a string and pulley
} 
arrangement, to the shaft of a microtorque potentiometer. Voltage changes through the potentiometer were graphically recorded and provided a record of conditional and unconditional eyelid activity.

The UCS consisted of a $100-\mathrm{msec}, 200-\mathrm{V}$ ac shock, delivered through a pair of chronically implanted tantalum wire electrodes, mounted approximately $1 \mathrm{~cm}$ apart and $1 \mathrm{~cm}$ below the left eye. Two CSs were used in the present experiment, one visual and one auditory. The visual CS consisted of a 600 -msec termination of chamber illumination. The auditory CS consisted of a $600-\mathrm{msec}$, $2,000-\mathrm{Hz}$ tone at $76 \mathrm{~dB}$ above $20 \mu \mathrm{N} / \mathrm{m}^{2}$.

Experimental design and procedure. The investigation consisted of four phases: (1) systematic adaptation to the conditioning chamber, restraining box, and eyelid recording apparatus; (2) preconditioning stimulus exposure; (3) interpolated delay period; (4) conditional eyeblink training. Subjects differed in their treatment during the preconditioning stimulus exposure phase of the experiment. Independent groups of rabbits received preexposure to both the CS and UCS presented in a trace conditioning manner (Group Trace), both the CS and UCS presented in a random manner (Group RDM), or neither the CS nor the UCS (Group N). Twenty-six rabbits were assigned to Group Trace, 23 to Group RDM, and 22 to Group N. The tone CS was used for approximately half the subjects in each group: 14 subjects in Group Trace, 11 subjects in Group RDM, and 12 subjects in Group N. The visual CS was used for the remaining subjects in each group.

Each subject participated in the experiment for each of 23 daily 60 -min sessions. On Day 1 , the rabbit was placed in the restraint box, the left side of the head was shaved, the shock electrodes were implanted, and a wound clip (for attaching the string of the potentiometer) was fastened to the rabbit's left upper eyelid. The animal then remained in the restraint box for the remainder of this first session. Day 2 consisted of further adaptation to the restraint box, conditioning chamber, and eyelid recording apparatus. On Days 3-7, subjects received their preconditioning exposure to the conditioning stimuli. During this preexposure phase, Group $\mathbf{N}$ subjects were simply further restrained in the conditioning apparatus. Subjects in Groups RDM and Trace received $20 \mathrm{CS}$ and 20 UCS presentations during each preexposure session. For both groups, the interval between CS presentations was $1.5,3.0$, or 4.5 min (mean: $3.0 \mathrm{~min}$ ), with the different intervals occurring according to a predetermined irregular sequence. For Group RDM, the 20 UCS presentations were randomly distributed in each preexposure session: Every .1-sec segment of each session had an equal probability of containing the UCS. For Group Trace, the UCS was presented $10 \mathrm{sec}$ following the offset of the CS, thereby resulting in a 10.6-sec interstimulus interval (ISI). (It was previously determined that no evidence of eyelid conditioning could be observed with this trace procedure.)

Following the preconditioning stimulus exposure phase, all subjects were left undisturbed in their home cages for the next 8 days (Days 8-15). Since a summation test of inhibition necessitates that there be an interval interpolated between suspected inhibitory training and inhibitory testing (for the training of an excitatory CS, see Rescorla, 1969), in the present retardation-of-acquisition test, a similar interval of sufficient duration for the training of an excitatory CS was interpolated between suspected inhibitory training (Phase 2) and CR acquisition testing (Phase 4).

Conditional eyelid training started immediately following the last day of the interpolated delay period, and was the same for all subjects: The UCS overlapped the last .1 sec of the CS, so the ISI was $.5 \mathrm{sec}$. All subjects received 20 acquisition trials during each of eight daily sessions (Days 16-23), with ITIs of $1.5,3.0$, or $4.5 \mathrm{~min}$ (mean: $3.0 \mathrm{~min}$ ).

During the preconditioning stimulus exposure phase of the experiment, eyeblinks were scored during the $.6 \mathrm{sec}$ CS for Group RDM and during the $10.6 \mathrm{sec}$ ISI for Group Trace. During the conditional eyelid training phase, eyblinks were scored during the .5 -sec ISI for all groups.

\section{Results}

As expected, no evidence of excitatory conditioning was obtained in either Group RDM or Group Trace during the preconditioning stimulus exposure phase of the experiment.

A mixed-design analysis of variance of the eyeblink conditioning acquisition data during the final phase of the experiment indicated a significant main effect of CS modality: visual vs. auditory $[\mathrm{F}(1,65)=18.55$, $\mathrm{p}<.001]$. Conditional response acquisition was slower in groups that received the visual CS than in groups that received the auditory CS. However, no interaction involving this CS modality variable was statisically significant.

Figure 1 presents the mean percentage of trials in which an eyeblink CR occurred for each of the 8 days of conditional eyelid training for Groups Trace RDM, and N, with the data collapsed across the CSmodality dimension. As shown in Figure 1, eyelid conditioning acquisition was retarded in both groups with prior experience with the conditioning stimuli (Trace and RDM) relative to the group that received no preconditioning stimulus exposure (Group N).

Statistical analyses of the data presented in Figure 1 indicated a significant Groups effect $[F(2,65)=6.88$, $\mathrm{p}<.005]$. Subsequent pairwise comparisons (Duncan's multiple range test) indicated that although the difference between Groups Trace and RDM was not significant, both groups evidenced fewer CRs than Group N (both ps $<.001$ ).

\section{Discussion}

If nonexcitatory trace conditioning involves an inhibitory learning process, it would be expected that such trace conditioning would retard subsequent ex-

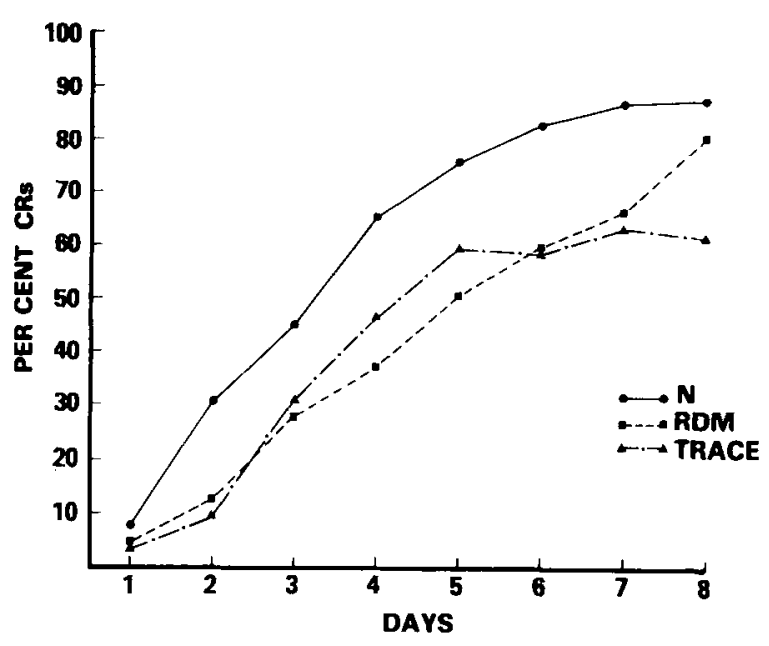

Figure 1. Mean percentage of daily trials in which a CR occurred for each of the $\mathbf{8}$ days of conditional eyeblink training for groups in Experiment 1. 
citatory $\mathrm{CR}$ acquisition. In the present experiment, Group Trace was slower to acquire the eyelid CR than Group $\mathbf{N}$, thus confirming this expectation.

Although retarded excitatory $\mathrm{CR}$ acquisition is a necessary property of an inhibitory stimulus, it is not a sufficient demonstration of such inhibition. Such retardation, for example, could have resulted because the preconditioning operations rendered the CS (and/or UCS) less salient (see Rescorla, 1969) or less effectively processed (see Wagner, 1976), rather than because the preconditioning procedure rendered the $\mathrm{CS}$ inhibitory. Indeed, in the present experiment, Group RDM was retarded in acquisition to about the same extent as Group Trace. The finding that random CS and UCS presentations retard acquisition confirms previous findings obtained with the rabbit eyelid preparation (Siegel \& Domjan, 1971, Experiment 2), as well as a variety of other conditioning preparations (e.g., Kremer, 1971; Siegel \& Domjan, 1971, Experiment 1; Tomie, 1976). The deleterious effect of random preexposure on subsequent excitatory conditioning has usually been interpreted as resulting from adaptational, attentional, or other noninhibitory decremental processes (e.g., Mackintosh, 1973; Rescorla, 1969). Thus it is possible that the retarded conditioning shown by Group Trace in the present experiment may have resulted from similar noninhibitory mechanisms.

Another noninhibitory interpretation of the Group Trace performance concerns CR timing. For subjects in Group Trace, the present retardation-of-acquisition test involved a CS -UCS interval shift from suspected inhibitory training to CR acquisition testing. The results of several experiments (Coleman \& Gormezano, 1971; Leonard \& Theios, 1967) have demonstrated that a switch in the CS-UCS interval may interfere with $C R$ acquisition at the new interval. Such interference presumably results because the timing of the CR learned during training with the original CS-UCS interval is incompatible with CR acquisition at the shifted CS-UCS interval. Even though there was no evidence of $C R$ acquisition with the trace conditioning procedure in the present experiment, it is possible that rabbits in Group Trace may have learned a weak excitatory association between the CS and UCS (see Sears et al., 1979). Conditioning to the trace CS may have been retarded during $C R$ acquisition testing because the trace CS elicited an incompatible timing expectancy, rather than because it elicited a conditional inhibitory process.

To ascertain if the retarded CR acquisition performance shown by subjects in Group Trace is attributable to conditional inhibition, it is necessary to assess the ability of the putatively inhibitory trace CS to reduce the expression of excitation of a simultaneously presented known excitatory stimulus. Such decreased excitation would be expected if the CS was inhibitory, but not if it simply did not command attention (Carlton \& Vogel, 1967; Reiss \& Wagner, 1972; Rescorla, 1969), was established as irrelevant (Mackintosh, 1973), was ineffectively processed (Wagner, 1976), or was weakly excitatory at a long ISI (see Sears et al., 1979). Thus a further experiment would be required to evaluate the effects of trace conditioning with a summation test.

\section{EXPERIMENT 2}

In Experiment 2, as in the previous experiment, different groups of rabbits initially received trace, random, or no preconditioning experience with a $C S$ and UCS. Subsequently, a CS other than that used in the initial phase of the experiment was made excitatory. Finally, the trace or random CS (or a novel CS in the case of subjects with no preconditioning stimulus exposure) was presented simultaneously with the known excitatory CS to evaluate the extent to which the expression of conditional excitation was affected.

\section{Method}

Subjects and Apparatus. The subjects were 72 experimentally naive rabbits of the same age, sex, and strain as those used in the previous experiment. The conditioning apparatus and details of the auditory and visual CSs and shock UCS were as described previously.

Preconditioning phase. In the present experiment as in the previous experiment, the subjects were first systematically adapted to the restraint and eyelid recording apparatus during two daily sessions. The preconditioning stimulus exposure phase of the experiment was conducted on each of the next 5 days. As described previously, during the preconditioning stimulus exposure phase, one group of rabbits was simply restrained in the conditioning apparatus, with no CS or UCS presentations (Group N), another group received 20 random presentations each of the CS and UCS (Group RDM), and a third group was presented with 20 pairings of the CS and UCS in a trace conditioning manner with a 10.6-sec ISI (Group Trace). Twenty-four rabbits were assigned to each of these three groups. For half the subjects in each group that received CS and UCS presentations during this preconditioning phase of the experiment (Groups RDM and Trace), the auditory CS was used. The visual CS was used for the remaining subjects in these two groups. The CS used in the preconditioning stimulus exposure phase of the experiment will be referred to in this paper as $\mathrm{CS}_{1}$.

Excitatory conditioning phase. Following preconditioning stimulus exposure, all subjects received excitatory eyelid training with the CS (auditory or visual) to which they had not been exposed during the preconditioning phase of the experiment. Group $N$ subjects, which received no preconditioning exposure to either $C S$, were randomly assigned to CS-modality conditions during this phase of the experiment, half the animals being trained with each CS. The CS used in the excitatory conditioning phase of the experiment will be reffered to as $\mathbf{C S}_{2}$. All subjects received 20 excitatory conditioning trials per day (mean ITI: $3 \mathrm{~min}$ ) for 8 days. On each trial, the UCS overlapped the last $100 \mathrm{msec}$ of $\mathrm{CS}_{2}$. 
The logic of the summation test of inhibition requires that the $\mathrm{CS}$ being tested $\left(\mathrm{CS}_{1}\right)$ be summated with an unequivocally excitatory $\mathrm{CS}\left(\mathrm{CS}_{2}\right)$. To insure that the present summation test used such an excitatory CS, subjects which did not display 9 CRs in any block of 10 consecutive trials during the course of excitatory eyelid conditioning were not used in the subsequent summation test phase of the experiment (and their data were eliminated from all phases of the experiment). Such a criterion of conditioning has been used in other studies from this laboratory involving this eyelid conditioning preparation (see Siegel, 1972).

Summation test of inhibition. The summation test phase of the experiment started the day after the last excitatory conditioning session, and was conducted over six daily sessions. As was the case in the prior phase of the experiment, each session consisted of 20 trials with a mean ITI of $3 \mathrm{~min}$. Fifteen of these daily trials consisted of compound CS presentations: The auditory and visual CSs were presented simultaneously. No UCS was presented on these compound trials. Since these compound CS presentations involved extinction trials to $\mathrm{CS}_{2}$, the remaining 5 trials of each daily session (Trials $1,7,9,15$, and 17 ) involved reinforced presentations of $\mathrm{CS}_{2}$ not compounded with $\mathrm{CS}_{1}$.

During summation testing, eyeblinks were scored during the $.5-\mathrm{sec}$ ISI for reinforced $\mathrm{CS}_{2}$ trials and during the total .6-sec duration of the compound stimulus for nonreinforced $\mathrm{CS}_{1}+\mathrm{CS}_{2}$ trials.

\section{Results}

Acquisition to $\mathbf{C S}_{\mathbf{2}}$. Following the excitatory conditioning phase of the experiment, a total of 11 of the original 72 subjects were eliminated from the study for failure to attain the criterion of conditioning to $\mathrm{CS}_{2}$ (9 CRs in 10 trials): 3 in Group N, 6 in Group RDM, and 2 in Group Trace. The remaining 61 subjects received further excitatory training with $\mathrm{CS}_{2}$ during the summation testing phase of the experiment.

Figure 2 presents the mean percentage of trials in which a CR occurred for all groups during each day of the excitatory conditioning phase of the experiment (top panel), and for the reinforced $\mathrm{CS}_{2}$ presentations during the summation testing phase of the experiment(bottom panel). The data from subjects dropped from the study for failure to meet the criterion of excitatory conditioning are not included in Figure 2.

As can be seen in the top panel of Figure 2, and as would be expected on the basis of the criterion of subject selection, all groups attained similar high levels of conditioning performance by the end of the excitatory conditioning phase of the experiment. A mixed-design analysis of variance of the data summarized in the top panel of Figure 2 revealed, however, that the groups differed in the rate of CR acquisition to $\mathrm{CS}_{2}[\mathrm{~F}(2,55)=7.17, \mathrm{p}<.005]$. Subsequent analyses (Duncan's multiple range test) indicated that all groups differed from each other (all ps $<.01$ ).

As indicated in the bottom panel of Figure 2, subjects in the different groups continued to display similar levels of conditioning on those five daily trials during the summation testing phase which consisted
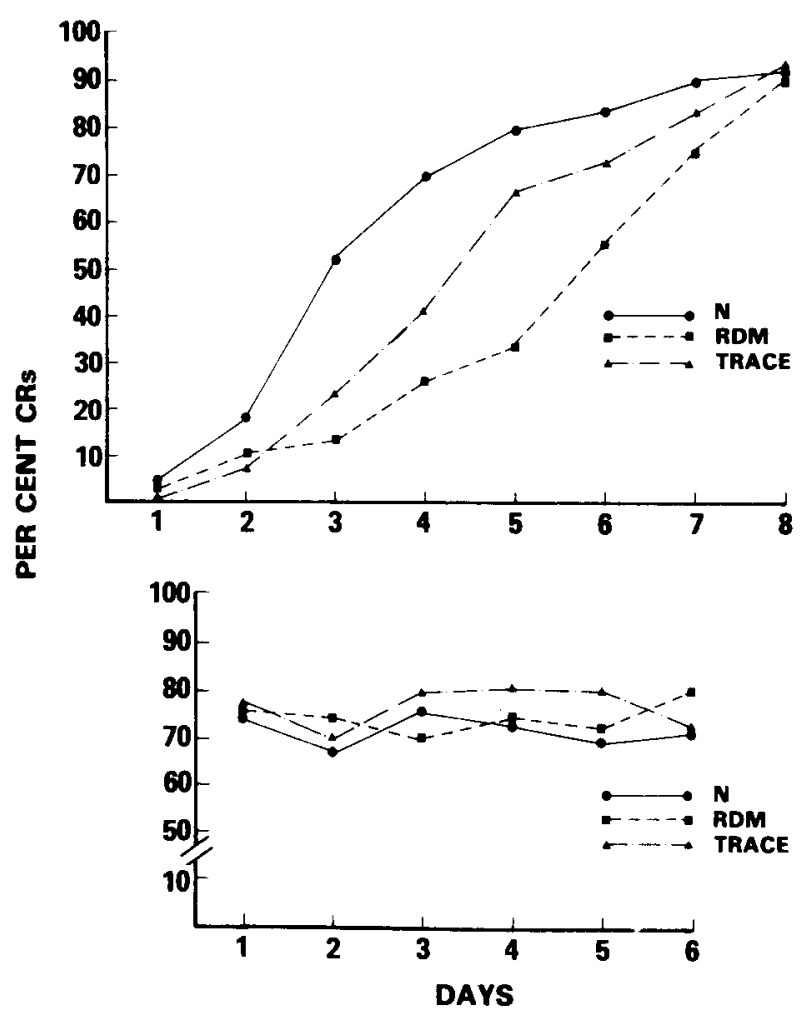

Figure 2. Mean percentage of daily trials in which a CR occurred to $\mathrm{CS}_{2}$ during each day of the excitatory conditioning phase (top panel) and for the five daily reinforced $\mathrm{CS}_{2}$ presentations during summation testing (bottom panel) in Experiment 2.

of reinforced $\mathrm{CS}_{2}$ presentations. A mixed design analysis of variance of the results summarized in the bottom panel of Figure 2 revealed no statistically significant main effects or interactions (all Fs $<1.29$ ). Therefore, at the time of summation testing, $\mathrm{CS}_{\mathbf{2}}$ was an effective excitatory CS for all groups, there being no appreciable difference in the level of conditioning to $\mathrm{CS}_{2}$ between groups.

Summation testing. The mean percentage of daily compound CS trials in which a CR occurred during each summation test session for all groups is shown in Figure 3. Examination of Figure 3 indicates that, although there was a slight tendency for the percentage CRs to decrease over the course of summation testing in all groups, Group Trace consistently evidenced the fewest CRs and Group RDM the most CRs, with Group $\mathbf{N}$ displaying an intermediate level of responding. Statistical analyses indicated that the effect of Sessions was significant $[F(5,75)=4.06$, $\mathrm{p}<.005$ ], but did not interact with Groups $(\mathrm{F}<1)$. The main effect of Groups was significant $[F(2,55)=4.01, p<.025]$, and pairwise comparisons (Duncan's multiple range test) revealed that Group Trace evidenced significantly fewer CRs than either of the other two groups (both ps $<.001$ ), and 


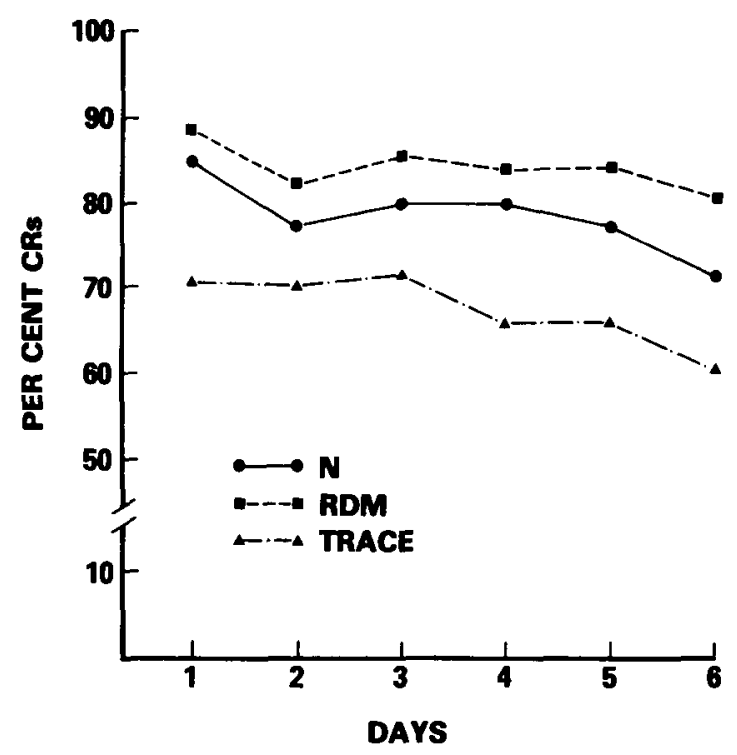

Figure 3. Mean percentage of daily trials in which a CR occurred for the 15 daily compound auditory-visual CS presentations during each day of summation testing in Experiment 2.

that Group $\mathrm{N}$ evidenced significantly fewer CRs than Group RDM ( $\mathrm{p}<.05)$.

To assess further the extent to which the expression of conditional excitation was affected on compound $\mathrm{CS}$ trials, the percentage of daily reinforced $\mathrm{CS}_{2}$ trials in which a $C R$ occurred was subtracted from the percentage of daily nonreinforced $\mathrm{CS}_{1}+\mathrm{CS}_{2}$ trials in which a CR occurred for each subject for each of the 6 days of summation testing. Only CRs occurring during $\mathrm{CS}_{1}+\mathrm{CS}_{2}$ trials with an onset latency less than $500 \mathrm{msec}$ were used in this comparison, since the CS-UCS interval on $\mathrm{CS}_{2}$ trials was only 500 msec. (The conclusions based on this analysis would be the same if the entire 600 -msec $\mathrm{CS}_{1}+\mathrm{CS}_{2}$ period were used.) Figure 4 presents the mean difference in the percentage of daily reinforced $\mathrm{CS}_{2}$ trials in which a CR occurred subtracted from the percentage of daily nonreinforced $\mathrm{CS}_{1}+\mathrm{CS}_{2}$ trials in which a $\mathrm{CR}$ occurred for each subject for each of the six summation test sessions. As may be seen in Figure 4, subjects in Groups RDM and $\mathrm{N}$ evidenced a slightly higher percentage of $\mathrm{CRs}$ on $\mathrm{CS}_{1}+\mathrm{CS}_{2}$ trials compared to $\mathrm{CS}_{2}$ trials. In comparison, subjects in Group Trace exhibited CRs on a smaller percentage of $\mathrm{CS}_{1}+\mathrm{CS}_{2}$ trials than on $\mathrm{CS}_{2}$ trials. A mixed-design analysis of variance of the data presented in Figure 4 revealed significant main effects of Groups $[F(2,55)=8.63, p<.001]$ and Sessions $[F(5,275)=2.44, p<.05]$. Subsequent pairwise comparisons (Duncan's multiple range test) indicated that Group Trace was reliably different from both Group RDM and Group N (both ps $<.001$ ), but that the latter two groups did not differ.

\section{Discussion}

The results of the present experiment demonstrated that the CS from the trace conditioning procedure reduced the expression of conditional excitation to the known excitatory CS with which it was summated more than when either the random CS or a novel stimulus was combined with the same excitator CS: When the trace $\mathrm{CS}_{1}$ was combined with the known excitatory $\mathrm{CS}_{2}$, fewer CRs were exhibited than when either the random $\mathrm{CS}_{1}$ or a novel stimulus was combined with $\mathrm{CS}_{2}$. In fact, when either the random $\mathrm{CS}_{1}$ or a novel stimulus was combined with the known excitatory $\mathrm{CS}_{2}$, there was a slightly greater percentage of CRs than when the excitatory $\mathrm{CS}_{2}$ was presented alone.

A further finding in the present experiment was the greater frequency of CRs exhibited on the compound summation test trials by subjects in Group RDM than by subjects in Group $N$ (Figure 3). The results of Experiment 1 demonstrated that Group RDM was retarded in acquisition relative to Group $N$. The Group RDM pattern of attenuated acquisition performance and augmented summation test performance is not readily interpretable by the various descriptions which have been proposed concerning the relevant effects of random experience with the conditioning stimuli (e.g., Benedict \& Ayres, 1972; Kremer, 1971; Kremer \& Kamin, 1971; Mackintosh, 1973; Rescorla, 1969). Although the results of the present experiment do not clarify the effects of random CS and UCS presentations, such clarification

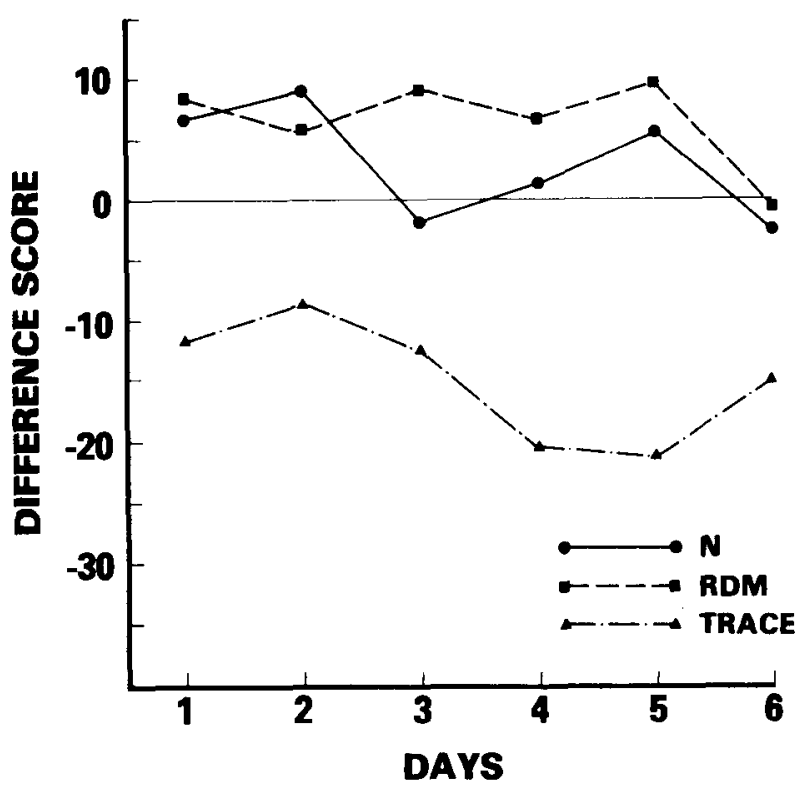

Figure 4. Mean difference in the percentage of $\mathrm{CS}_{2}$ trials in which a $\mathbf{C R}$ occurred subtracted from the percentage of $\mathrm{CS}_{1}+\mathrm{CS}_{2}$ trials in which a CR occurred for each subject for the 6 days of summation testing for all groups in Experiment 2. 
was not the purpose of the experiment. Rather, Group RDM, like Group N, was included in the design of the present experiment to provide a baseline with which to compare the summation test performance of Group Trace, both types of comparisons having been justified on theoretical and empirical grounds in previous experiments incorporating summation tests of inhibition (see Moscovitch \& LoLordo, 1968; Rescorla, 1969, 1971). The results of this experiment clearly indicated that, compared to either of the two control groups, the trace CS suppressed responding to the known excitatory CS.

\section{GENERAL DISCUSSION}

The trace conditioning procedure used in the present experiments was an effective inhibitory training procedure. The trace CS was retarded in the acquisition of excitatory properties (Experiment 1), and reduced the expression of excitatory CRs by a known excitatory CS with which it was compounded (Experiment 2). Such evidence of inhibition in both retardation-of-acquisition and summation tests would appear to establish the trace CS as a conditional inhibitor (see Rescorla, 1969).

The finding that the trace conditioning paradigm may be an effective inhibitory training procedure is not readily interpretable by most formulations of trace conditioning. Hull (1943, p. 172) hypothesized that presentation of the CS initiated a neural trace which required a period of approximately $450 \mathrm{msec}$ to reach a maximal level of activity. A number of subsequent investigators have sought to verify the form of this postulated stimulus molar trace by examining the acquisition of an excitatory $C R$ at various trace intervals (Meredith \& Schneiderman, 1967; Schneiderman, 1966; Smith, 1968; Smith, Coleman, \& Gormezano, 1969). An assumption of this research methodology is that the empirical function relating ISI and acquisition performance is determined solely by the passive decay of the CS-elicited stimulus trace. Given this assumption, failure to observe excitatory conditioning at a particular ISI has been taken as evidence that the intensity of the CS trace at that time was so weak as to preclude effective contiguous pairing of the $\mathrm{CS}$ and UCS. The results of the present experiments suggest that the ISI function in trace conditioning may be determined not only by excitatory associations, but also by inhibitory associations.

Although experience with the CS and UCS in a random manner retarded acquisition of excitatory conditioning (Experiment 1), the CS from the random procedure did not reduce the expression of excitatory CRs in the summation test (Experiment 2). The finding that a random procedure may retard excitatory conditioning but fail to produce evidence of inhibition in a summation test has also been reported by Kremer (1971) in a different conditioning situation. Thus, the retarded acquisition following random presentations of the CS and UCS evidently results from some process other than conditional inhibition.

Recently, Kehoe, Gibbs, Garcia, and Gormezano (1979) have shown that excitatory conditioning to the first element of a serial compound trace CS may occur at CS-UCS trace intervals much longer (e.g., $18.75 \mathrm{sec}$ ) than those normally effective in producing excitatory conditioning to a single-cue trace CS. Although such excitatory conditioning in these experiments was very pronounced early in testing, with further testing the level of responding to the first component of the serial trace CS ultimately declined to a very low level or disappeared altogether. Kehoe et al. (1979) suggested that the ultimate decline in excitatory CRs to the first element of the serial trace CS may have been due to the development of conditional inhibition based on a long CS-UCS trace interval. The results of the present experiments demonstrate that conditional inhibition may develop with long trace conditioning intervals, and thus support this suggestion.

In the present experiments, evidence of conditional inhibition was obtained following training with a 10-sec trace conditioning procedure in the rabbit eyelid preparation. The results of experiments with different conditioning preparations demonstrate, however, that excitatory conditioning may be obtained with trace intervals longer than that employed in the present experiments (e.g., Ellison, 1964; Kamin, 1961). Recently, Sears et al. (1979) suggested that differences in the conditionability of different response systems with the same temporal arrangement of CS and UCS may be due to evolutionary considerations. With respect to the eyelid response, Sears et al. (1979) suggested that the occurrence of the eyeblink is most adaptive to the organism if closure occurs just prior to onset of UCS. However, with other response systems (e.g., salivation, fear), they suggested that a different CR-UCS temporal relationship might be more adaptive. Thus, the associative outcome of any particular temporal arrangement of CS and UCS may be determined by, among other factors, the response system being monitored.

\section{REFERENCES}

Benedict, J. O., \& Ayres, J. J. B. Factors affecting conditioning in the truly random control procedure. Journal of Comparative and Physiological Psychology, 1972, 78, 323-330. 
Carlton, P., \& Vogel, J. R. Habituation and conditioning. Journal of Comparative and Physiological Psychology, 1967, 63, 348-351.

Coleman, S. R., \& Gormezano, I. Classical conditioning of the rabbit's (Oryctolagus cuniculus) nictitating membrane response under symmetrical CS-US interval shifts. Journal of Comparative and Physiological Psychology, 1971, 77, 447-455.

Ellison, G. D. Differential salivary conditioning to traces. Journat of Comparative and Physiological Psychology, 1964, 57, 373-380.

Gormezano, I. Classical conditioning. In J. B. Sidowski (Ed.), Experimental methods and instrumentation in psychology. New York: McGraw-Hill, 1966.

Hull, C. L. Principles of behavior. New York: Appleton-CenturyCrofts, 1943.

KAMIN, L. J. Trace conditioning of the conditioned emotional response. Journal of Comparative and Physiological Psychology, 1961, 54, 149-153.

Keirof, E. J., Gibbs, C. M., Garcia, E., \& Gormezano, I. Associative transfer and stimulus selection in classical conditioning of the rabbit's nictitating membrane response to serial compound CSs. Journal of Experimental Psychology: Animal Behavior Processes, 1979, 5, 1-18.

KREMER, E. F. Truly random and traditional control procedures in CER conditioning in the rat. Journal of Comparative and Physiological Psychology, 1971, 76, 441-448.

KrEmER, E. F., \& Kamin, L. J. The truly random control procedure: Associative or nonassociative effects in rats. Journal of Comparative and Physiological Psychology, 1971, 74, 203-210.

Leonard, D. W., \& Theios, J. Effect of CS-US interval shift on classical conditioning of the nictitating membrane response in the rabbit. Journal of Comparative and Physiological Psychology, 1967, 63, 355-358.

Mackintosh, N. J. Stimulus selection: Learning to ignore stimuli that predict no change in reinforcement. In R. A. Hinde \& J. Stevenson-Hinde (Eds.), Constraints on learning. London: Academic Press, 1973.

Meredith, A. L., \& Schneiderman, N. Heart rate and nictitating membrane classical discrimination conditioning in rabbits under delay versus trace procedures. Psychonomic Science, $1967,9,139-140$.

Moscovitcu, A., \& LoLondo, V. M. Role of safety in the Pavlovian backward fear conditioning procedure. Journal of Comparative and Physiological Psychology, 1968, 66, 673-678.

Pavlov, I. P. Conditioned reflexes. Oxford: Oxford University Press, 1927.
Reiss, S., \& Wagner, A. R. CS habituation produces a "latent inhibition" effect but no active "conditioned inhibition." Learning and Motivation, 1972, 3, 237-245.

Resconla, R. A. Pavlovian conditioned inhibition. Psychological Bulletin, 1969, 72, 77-94.

Rescorla, R. A. Summation and retardation tests of latent inhibition. Journal of Comparative and Physiological Psychology, 1971, 75, 77-81.

Schne Ide RMan, $N$. Interstimulus interval function of the nictitating membrane response of the rabbit under delay versus trace conditioning. Journal of Comparative and Physiological Psychology, 1966, 62, 397-402.

Sears, R. J., Baker, J. S., \& Frey, P. W. The eye blink as a time-locked response: Implications for serial and second-order conditioning. Journal of Experimental Psychology: Animal Behavior Processes, 1979, 5, 43-64.

SIEGEL, S. Latent inhibition and eyelid conditioning. In A. H. Black \& W. F. Prokasy (Eds.), Classical conditioning II. New York: Appleton-Century-Crofts, 1972.

Siegel, S., \& Domjan, M. Backward conditioning as an inhibitory procedure. Learning and Motivation, 1971, 2, 1-11.

Siegel, S., \& Domjan, M. The inhibitory effect of backward conditioning as a function of the number of backward pairings. Bulletin of the Psychonomic Society, 1974, 4, 122-124.

Smiтh, M. C. CS-US interval and US intensity in classical conditioning of the rabbit's nictitating membrane response. Journal of Comparative and Physiological Psychology, 1968, 66, 679-687.

Smith, M. C., Coleman, S. R., \& Gormezano, I. Classical conditioning of the rabbit's nictitating membrane response at backward, simultaneous, and forward CS-US intervals. Journal of Comparative and Physiological Psychology, 1969, 69, 226-231.

TомIE, A. Interference with autoshaping by prior context conditioning. Journal of Experimental Psychology: Animal Behavior Processes, 1976, 2, 323-334.

Wagner, A. R. Priming in STM: An information processing mechanism for self-generated or retrieval-generated depression in performance. In T. J. Tighe \& R. N. Keaton (Eds.), Habituation: Perspectives from child development, animal behavior, and neurophysiology. Hillsdale, N.J: Erlbaum, 1976.

(Received for publication December 29, 1978; revision accepted June 22, 1979.) 